\title{
Tumor-Specific Cell-Mediated Immunity in Household Contacts of Cancer Patients
}

\author{
Vera S. Byers, Alan S. Levin, Adeline J. Hackett, and \\ H. Hugh Fudenberg \\ From the Departments of Medicine and Dermatology, School of Medicine, \\ University of California, San Francisco, California 94143, the School of \\ Public Health, University of California, Berkeley, California 94720, and \\ Western Laboratories, Oakland, California 94609
}

\begin{abstract}
A B S T R A C T Patients with osteogenic sarcoma (and related tumors), hypernephroma, and breast carcinoma, and their household contacts were tested for tumorspecific cell-mediated immunity against these tumors with the use of a short-term chromium-51 release assay. This assay, reproducible over many months and well-correlated with the clinical course of the patients, was used to demonstrate that household contacts of patients with osteogenic sarcoma and breast carcinoma have specific immunity against the tumor type with which they have been in contact. In both types of tumors, the range of cytotoxicity values produced by lymphocytes from the household contacts was significantly higher than that of the normal population. The incidence of immunity was much higher in household contacts of patients with breast carcinoma than in those of patients with osteogenic sarcoma. Immunity was found with equal frequency in men and women, as well as in genetically and nongenetically related household contacts (guardians, adopted children, spouses). Immunity against hypernephroma was not demonstrated in either patients with hypernephroma or their household contacts.
\end{abstract}

\section{INTRODUCTION}

The occurrence of tumor-specific immunity in normal humans who had been in contact with persons with cancers has been alluded to in several reports. Hellström, Hellström, Bill, Pierce, and Yang described cell

Dr. Byers was the recipient of NIH Postdoctoral Fellowship 5 FO 2AI 53320. Dr. Levin was the recipient of American Cancer Society Faculty Research Award PRA 88.

Received for publication 17 October 1973 and in reviscd form 4 November 1974. mediated-immunity to neuroblastoma in mothers of infants with that tumor (1). Morton and Malmgren demonstrated a high incidence of tumor-specific antibodies in family members of osteogenic sarcoma patients (2). This, in conjunction with their other studies, was interpreted as evidence for a possible viral etiology in some human cancers (3-5).

We selected three histologically different tumor types, osteogenic sarcoma, hypernephroma, and breast carcinoma, and performed a series of experiments to determine if household contacts of individuals with these tumors demonstrated higher than normal levels of tumor-specific cell-mediated cytotoxicity against cell lines derived from these tumors.

Individuals with osteogenic sarcoma or breast carcinoma who are immune to their own tumor will also demonstrate immunity against the same histological type of tumor from another individual (6). Therefore, representative tumor cell lines derived from the three tumor types were used as target cells in a $3-\mathrm{h}$ chromium-51 release assay. A random sample of normal individuals who had no known contact with carcinoma was used as a control population for carcinoma immunity; a random sample of normal individuals who had no known contact with sarcoma was used as the control population for sarcoma immunity. The reactions of the control group against these tumor cells were compared with those of household contacts of cancer patients with one of three tumor types. We found that the household contacts of patients with osteogenic sarcoma and with breast carcinoma had a significantly higher level of tumor-specific immunity directed against the histologic type of cancer to which they were exposed. We found no such incidence of 
TABLE I

Characteristics of Cell Lines Used in the Cytotoxicity Assay

\begin{tabular}{|c|c|c|c|c|c|c|c|c|c|c|c|c|}
\hline \multirow[b]{2}{*}{ Cell line } & \multirow{2}{*}{$\begin{array}{l}\text { Donor } \\
\text { sex }\end{array}$} & \multirow[b]{2}{*}{ Origin } & \multirow[b]{2}{*}{ Isolated by } & \multirow{2}{*}{$\begin{array}{l}\text { Passage } \\
\text { used }\end{array}$} & \multicolumn{3}{|c|}{ Media lysis } & \multicolumn{3}{|c|}{ Water lysis } & \multirow[b]{2}{*}{ Tumorogenicity } & \multirow[b]{2}{*}{ Reference } \\
\hline & & & & & Mean & $\mathrm{SD}$ & $\mathrm{SE}$ & Mean & $\mathrm{SD}$ & $\mathrm{SE}$ & & \\
\hline & & & & & \multicolumn{3}{|c|}{$\%$ of total } & \multicolumn{3}{|c|}{$\%$ of total } & & \\
\hline BT-20 & F & Breast carcinoma & Lasfargues & $33-35$ & 28.6 & 8 & 3 & 44.8 & 10.5 & 4 & $\begin{array}{l}\text { ATS mice,* slow- } \\
\text { growing tumors }\end{array}$ & $7-10$ \\
\hline ALAb 496 & F & Breast carcinoma & Sykes & $34-36$ & 24 & 9 & 3.4 & 37 & 11.8 & 4.5 & & $9,10,11$ \\
\hline Hs $736 \mathrm{~T}$ & $\mathbf{M}$ & Fibrosarcoma & NBRL & 4 & 20 & id§ & id & 35 & id & id & & \\
\hline Hs 736sk & $\mathbf{M}$ & Skin & NBRL & 4 & 27 & id & id & 17 & id & id & & \\
\hline A 498 & F & Hypernephroma & Giard & $26-28$ & 14.6 & 6 & 0.9 & 41.5 & 12.6 & 1.8 & $\begin{array}{l}\text { ATS mice, } \\
\text { carcinoma in } \\
\text { young mice }\end{array}$ & 12 \\
\hline Hs $706 \mathrm{~T}$ & F & $\begin{array}{l}\text { Giant cell } \\
\text { sarcoma }\end{array}$ & NBRL & 7 & 16.8 & 3.3 & 1.7 & 26 & 2 & 1 & & \\
\hline Hs 706sk & $\mathrm{F}$ & Skin & NBRL & 7 & 31.7 & id & id & 41.6 & id & id & & \\
\hline Te 85 & $\mathrm{~F}$ & Osteosarcoma & MacAllister & $17-19$ & 22 & 7.1 & 1.0 & 40.4 & 9.4 & 1.4 & & 8,13 \\
\hline Hs 699T & $\mathbf{M}$ & Hypernephroma & NBRL & 10 & 30 & id & id & 40 & id & id & & \\
\hline Hs 699sk & $\mathbf{M}$ & Skin & NBRL & 6 & 18 & id & id & 35 & id & id & & \\
\hline Hs $715 \mathrm{~T}$ & $\mathbf{M}$ & Hypernephroma & NBRL & 8 & 29 & id & id & 39 & id & id & & \\
\hline Hs 715sk & $\mathbf{M}$ & Kidney & NBRL & 10 & 13 & 6.2 & 4.4 & 28 & 7 & 5 & & \\
\hline
\end{tabular}

* Mice treated with antithymocyte serum.

‡ Naval Biomedical Research Laboratories, Oakland, Calif.

\& Insufficient data.

elevated immunity in either the patients with hypernephroma or their household contacts.

\section{METHODS}

Cell lines. The human cell lines used in this study are listed in Table I (7-13). All Hs-prefixed cell lines were isolated by the Owens differential trypsinization technique (14). All cell lines were propagated in antibiotic-free medium, either Dulbecco modified medium (Grand Island Biological Co., Grand Island, N. Y.) with $10 \%$ fetal calf serum (DEM-FCS), ${ }^{1}$ or minimal Eagle's medium with $10 \%$ FCS (MEM-FCS). Cells were subcultured at confluence with trypsin-EDTA (Gibco) and were frozen for storage in $10 \%$ dimethyl sulfoxide (DMSO) in DEM-FCS. One ampule of each frozen passage level was tested for mycoplasma contamination by Dr. L. Hayflick, Stanford University, using electron microscopy, and found negative. Other ampules from the same lot were thawed and used in the cytotoxicity assay. All cell lines were shown to be free of HeLa tumor cells by chromosome analysis and isoenzyme mobility patterns (8). Some of the cell lines were tested for ability to produce tumors in immunosuppressed mice. Karyology was performed on the tumor cells, usually within three passage levels of use; these studies verified in all cases that cell lines isolated in other laboratories retained their abnormal karotypes.

Although it is not possible to state that a culture is composed of pure tumor cells and therefore completely

${ }^{1}$ Abbreviations used in this paper: CI, cytotoxicity index; DEM-FCS, Dulbecco modified medium with $10 \%$ FCS; DMSO, dimethyl sulfoxide; FCS, fetal calf serum; Fx, fluorescein-labeled; HBSS, Hanks' balanced salt solution; $\mathrm{HHC}$, household contact; $\mathrm{HHC}_{\mathrm{br}}, \mathrm{HHC}$ of breast carcinoma patient; $\mathrm{HHC}_{\mathrm{hn}}, \mathrm{HHC}$ of hypernephroma patients; $\mathrm{HHC}_{\mathrm{os}}, \mathrm{HHC}$ of osteogenic sarcoma patients; MEM-FCS, minimal Eagle's medium with $10 \%$ FCS; RPMI-FCS, RPMI 1640 with $10 \%$ FCS and antibiotics; SRBC, sheep red blood cells. free of fibroblasts or other cellular contaminents, one can state that the vast majority of cells in a specific population are homogeneous tumor cells with abnormal karyotype, glucose-6-phosphate dehydrogenase patterns, and/or sex chromosomes matching those of the donor (8). This was the case with the cell lines used in this study.

To avoid genetic drift, only the three passage levels listed in Table I were used in the assay. This increased the probability of homogeneity in the target cell line preparations. That these cells were homogeneous is shown by the fact that lymphocytes tested on the same day from the same donor reacted the same on all three passage levels of each tumor cell line.

Freezing and storage of cells. Both target cells and lymphocytes (separated on Ficoll-Hypaque) were suspended in a final concentration of approximately $1 \times 10^{7}$ cells $/ \mathrm{ml}$ in a prechilled solution of MEM-FCS with $10 \%$ DMSO. $1-\mathrm{ml}$ aliquots were added to ampules, which were then flame-sealed and placed overnight in a $-70^{\circ} \mathrm{C}$ freezer in a pipette can completely wrapped with 2 -in-thick foam rubber to allow slow cooling. The ampules were then transferred to a liquid nitrogen container. When needed, the cells were rapidly thawed by dropping the ampule in ethanol, $37^{\circ} \mathrm{C}$. The ampules were opened just as the last ice crystal was dissolving. The contents were then slowly diluted with MEM-FCS at $37^{\circ} \mathrm{C}$ and washed twice with Hanks' balanced salt solution (HBSS, Gibco). The viability of the tumor cells ranged between $85-98 \%$ by trypan blue exclusion test. Lymphocytes were less stable to freezing, and their viability varied greatly upon thawing. They were used in the assay only if they were over $96 \%$ viable by trypan blue exclusion.

Target cells. Tumor cells were trypsinized just at confluence. They were then washed once in HBSS, and each target cell suspension was incubated in a total volume of 1-2 $\mathrm{ml}$ of RPMI 1640 (Gibco) with $0.1 \mathrm{ml}\left[{ }^{51} \mathrm{Cr}\right.$ ]sodium chromate (New England Nuclear, Boston, Mass., sp act $1 \mathrm{mCi} / \mathrm{ml}$, used through one half-life only) at $37^{\circ} \mathrm{C}$ for $30 \mathrm{~min}$. They were washed by layering them over and 
TABLE II

Raw Data from Replicate Samples in a Representative Experiment with Te 85, Osteogenic Sarcoma

\begin{tabular}{|c|c|c|c|c|c|}
\hline \multirow[b]{2}{*}{ Treatment of target cells* } & \multirow[b]{2}{*}{$\begin{array}{c}\text { Replicate } \\
\text { samples }\end{array}$} & \multirow[b]{2}{*}{$\begin{array}{l}\text { Mean of } \\
\text { replicates }\end{array}$} & \multirow[b]{2}{*}{$\mathrm{SD}$} & \multicolumn{2}{|c|}{ CIf } \\
\hline & & & & $\begin{array}{l}\text { Individual } \\
\text { replicates }\end{array}$ & Average \\
\hline \multirow[t]{4}{*}{ Water lysis } & 3,574 & 3,590 & 56 & & \\
\hline & 3,557 & & & & \\
\hline & 3,556 & & & & \\
\hline & 3,674 & & & & \\
\hline \multirow[t]{4}{*}{ Spontaneous lysis } & 1,306 & 1,343 & 27 & & \\
\hline & 1,342 & & & & \\
\hline & 1,370 & & & & \\
\hline & 1,354 & & & & \\
\hline \multirow[t]{3}{*}{ Lymphocyte lysis } & 2,017 & 2,042 & 36.4 & 30 & 31.0 \\
\hline & 2,084 & & & 33 & \\
\hline & 2,026 & & & 30 & \\
\hline
\end{tabular}

* Total cpm incorporated into $5 \times 10^{4}$ target cells $=8,342$.

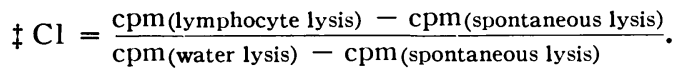

centrifuging them through a 15-ml FCS (Gibco) gradient; the cells were resuspended in HBSS and immediately recentrifuged. They were resuspended to a final concentration of $5 \times 10^{4}$ cells $/ \mathrm{ml}$ in RPMI 1640 with antibiotics and $10 \%$ FCS (RPMI-FCS). $1 \mathrm{ml}$ of this cell suspension was placed in small Petri dishes (Falcon 3001, Falcon Plastics, Div. of BioQuest, Oxnard, Calif.) and either preincubated for $3 \mathrm{~h}$ before the addition of lymphocytes (BT-20 and ALAb cell lines) or mixed with lymphocytes immediately.

Lymphocyte separation. Ficoll-Hypaque: Peripheral blood was drawn into a syringe filled with sodium heparin (3M Co., Medical Products Div., St. Paul, Minn., final concentration $50 \mathrm{U} / \mathrm{ml}$ ) and layered on a Ficoll-Hypaque gradient. The lymphocytes were separated by centrifugation, and washed two times in HBSS.

Column: $40 \mathrm{ml}$ of peripheral blood was layered over 4-mm glass beads (VWR Scientific Div., UNIVAR, San Francisco, Calif.) that covered the bottom of a sterile 500$\mathrm{ml}$ Erlenmeyer flask and were gently swirled by hand for 15-30 min until the blood was defibrinated. The blood was lightly centrifuged and the buffy coat was separated from the serum and red cells. The buffy coat was diluted $1: 1$ in HBSS, and poured over a sterile column formed by packing a 12-ml syringe with $1 \mathrm{~g}$ of nylon wool (Fenwal Inc., Ashland, Mass.) presoaked with HBSS. The column and cells were incubated at $37^{\circ} \mathrm{C}$ for $30 \mathrm{~min}$ and gently washed through with $30 \mathrm{ml}$ HBSS. The eluate was centrifuged and resuspended in HBSS to the original volume added to the column. The suspension was then layered on Ficoll-Hypaque and the lymphocytes were separated by centrifugation. They were then washed twice in HBSS and resuspended to the desired concentration. These lymphocytes are depleted of a population of cells with surface immunoglobulin (" $B$ " cells), consistent with the finding of Julius, Simpson, and Herzenberg (15).

Assay. The lymphocytes were adjusted to a final concentration ranging from $1 \times 10^{5}$ to $4 \times 10^{6}$ cells $/ \mathrm{ml}$ in RPMI-FCS. When $1 \mathrm{ml}$ of each suspension was mixed with $5 \times 10^{4}$ tumor cells, lymphocyte: target cell ratios of
2:1 through $80: 1$ were obtained. This mixture was incubated for $3 \mathrm{~h}$ at $37^{\circ} \mathrm{C}$ in moist $5 \% \mathrm{CO}_{2}$, on a rocking platform. The supernatant fluid was then aspirated from the dishes into small test tubes and the cell debris removed by centrifugation. The resulting supernatant fluid was decanted and counted in a gamma counter (Packard autogamma spectrometer, Packard Instrument Co., Inc., Downers Grove, III.). A cytotoxicity index (CI) was obtained with the use of the formula shown in Table II. In this formula, "water lysis" refers to the counts per minute in the supernatant fraction of dishes of target cells that contain $1 \mathrm{ml}$ water rather than $1 \mathrm{ml}$ lymphocyte suspension $(C I=100)$, and "media control" refers to radioactivity in the supernatant fluid of similar dishes that contain $1 \mathrm{ml}$ media without lymphocytes $(\mathrm{CI}=0)$. The water lysis was more constant from test to test than the "freeze-thaw" value, even though the total number of counts releasible was much lower. This was therefore routinely used as an approximation of the maximal amount of chromium-51 releasible from the target cells. The water lysis value, however, measures only the amount of chromium-51 incorporated into soluble proteins and liberated by osmotic lysis of the cells. In contrast, lymphocyte-mediated lysis causes both osmotic lysis and enzymatic degradation of the cell membranes (16-17). Thus lymphocyte-mediated lysis was often higher than the water lysis value. We therefore refer to $C I$ in units rather than as a percent.

Several preliminary experiments established that there was little difference between CI values obtained after 3 or $6 \mathrm{~h}$ incubation. However, after a 24-h incubation all parameters were increased (media control, water lysis, and lymphocyte lysis values) and, in many cases, specificity was decreased. That is, individuals who did not lyse control cell lines in the $3 \mathrm{~h}$ incubation did so after $24 \mathrm{~h}$. We therefore used a standard 3-h incubation.

Enumeration of $B$-cells. Separated lymphocytes were adjusted to $2 \times 6$ cells $/ \mathrm{ml}$ in phosphate-buffered saline (PBS). Fluorescein-labeled $(\mathrm{Fx})$ goat anti-human immunoglobulin (FxIgG, FxIgM, FxIgA, purchased from Bur- 


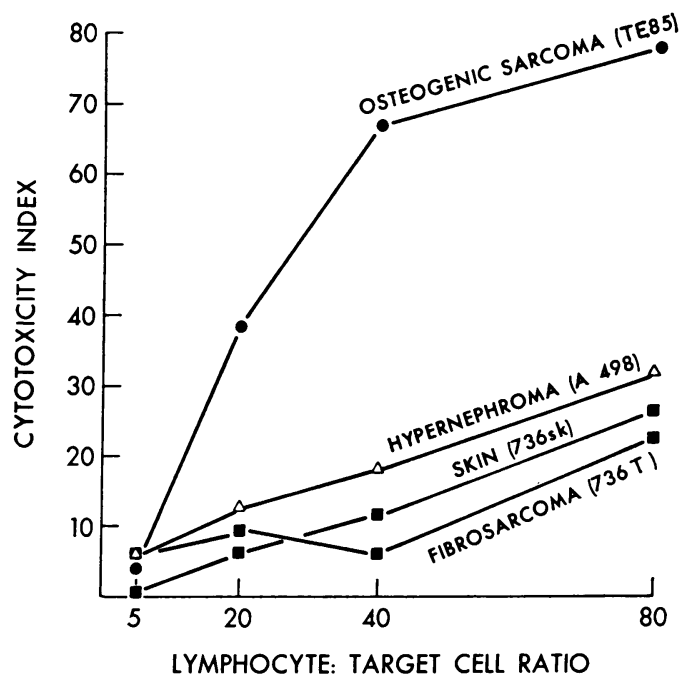

FIGURE $1 \mathrm{CI}$ as a function of increasing lymphocyte: target cell ratios. Lymphocytes taken from an osteogenic sarcoma patient shortly before amputation of a small, sclerosing tumor were tested against osteosarcoma cell line (Te 85), hypernephroma cell line (A 498), fibrosarcoma cell line $(736 \mathrm{~T})$, and the fibroblast cell line from the same patient (736sk). These data were selected as typical of the reaction. The $80: 1$ lymphocyte: target cell ratio is on the plateau region of the curve, where minimal variation is encountered. All subsequent values are expressed at the $80: 1$ ratio. Additional data concerning the clinical correlates of reactivity with the $\mathrm{Te} 85$ cell line are published in the accompanying paper (21).

roughs-Wellcome \& Co., Inc., Tuckahoe, N. Y.) was added to the lymphocytes at a final dilution of $1: 10$, and incubated at $4^{\circ} \mathrm{C}$ for $30 \mathrm{~min}$. The cells were then washed twice in cold PBS and scored for surface immunoglobulins with the use of phase and fluorescent microscopy (Leitz fluorescent microscope; E. Leitz, Inc., Rockleigh, N. J.).

Rosette-forming cells. After the incubation period of the assay, excess lymphocytes were removed from the Petri dishes by washing gently once with HBSS. $2 \times 10^{7}$ sheep red blood cells (SRBC) in $1 \mathrm{ml}$ RPMI 1640 were added to the dishes. After an incubation period of $30 \mathrm{~min}$, the supernatant fluid was gently aspirated and the dish was gently washed once with RPMI 1640.

Staining of target cells: lymphocytes. A small sterile circular glass cover slip was fixed to the bottom of the Petri dish by heating the tip of a needle and melting four dots of plastic at equal intervals on the circumference of the glass slip. Lymphocytes and target cells were added to these dishes and the assay was carried out as usual. The cover slips were removed, washed once in HBSS, fixed, and stained according to one of the following methods: fixed in a 9:1 mixture of ethanol and methanol for $5 \mathrm{~min}$ at $4^{\circ} \mathrm{C}$, damped dry, and either stained with Wright-Giemsa stain, or incubated with fluorescein-conjugated anti-human polyvalent immunoglobulins; or incubated unfixed with the same fluorescein-conjugated antisera at $4^{\circ} \mathrm{C}$ for $30 \mathrm{~min}$, washed twice, and examined on a Leitz fluorescent phase microscope. Controls included lymphocytes from the same individual, incubated in Petri dishes in the absence of tumor cells for $3 \mathrm{~h}$, aspirated into test tubes, and centrifuged in a table-top Sero-fuge (Clay-Adams Inc., Parsippany, N. J.) $(2,000 \mathrm{rpm})$ for $10 \mathrm{~min}$. The cell button was resuspended in $\mathrm{PBS}$ and treated with a 1:10 dilution of FxIgG and FxIgM at $4^{\circ} \mathrm{C}$ for $30 \mathrm{~min}$. The cells were washed twice in cold PBS and placed on microscope slides.

Household contacts. An individual was classified as a household contact of a patient with hypernephroma or osteogenic sarcoma if he or she had been in close contact with a patient with an active tumor for at least 6 mo before being tested. Household contacts of patients with breast carcinoma ranged in age from 5 to $50 \mathrm{yr}$ and had spent the past $5 \mathrm{yr}$ in contact with the patients (all of whom either had active metastatic disease or had had a mastectomy within the past $3 \mathrm{yr}$ ). Household contacts of osteogenic sarcoma and hypernephroma ranged in age between 18 and $52 \mathrm{yr}$.

Normal population. Individuals classified as normal for this study had had no known contact with a patient with carcinoma (if included with the control group for breast carcinoma or hypernephroma) or with a patient with a sarcoma (if included in the control group for osteogenic sarcoma). The normal population was matched to the

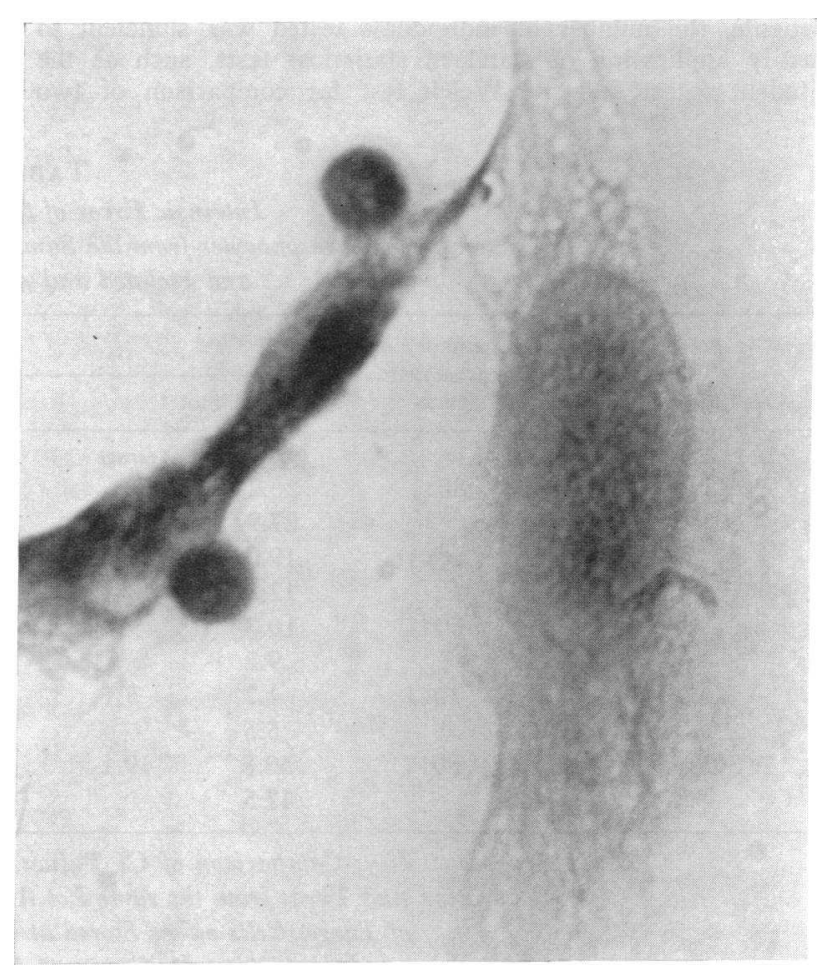

FIGURE 2 Wright-Giemsa stain of the cytotoxicity reaction at the end of the 3 -h incubation period; osteogenic sarcomaderived tumor cells ( $\mathrm{Te} 85$ ) and lymphocytes from an immune donor were used. The lymphocytes can be seen fused to the target cell membrane of the lysed cell, and an adjacent tumor cell without lymphocytes adherent is not lysed. Fluorescence microscopy of similar preparations reacted with fluorescein anti-human immunoglobulins demonstrated that these cells lack surface immunoglobulin receptors. Monocytes were occasionally but not often seen adhering to the target cells. They were neither necessary nor sufficient for tumor cell lysis in this assay. 
TABLE III

Comparison of One Person's Lymphocytes Separated on Ficoll-Hypaque with those Separated on Nylon Wool Columns

\begin{tabular}{ccc}
\hline $\begin{array}{c}\text { Lymphocyte:target } \\
\text { cell ratio* }\end{array}$ & Ficoll-Hypaque & $\begin{array}{c}\text { Nylon wool } \\
\text { column§ }\end{array}$ \\
\hline & $C I$ & $C I$ \\
$40: 1$ & 34.8 & 33.9 \\
$40: 1$ & 20.2 & 20.8 \\
\hline
\end{tabular}

* Assayed on Te 85 , osteogenic sarcoma.

$\ddagger$ Lymphocytes are $15-21 \%$ surface immunoglobulin-bearing cells after separation.

\$ Lymphocytes are 1-2\% surface immunoglobulin-bearing cells after separation.

household contact population by sex and age range. These individuals had no known disease.

Statistics. For the studies on normal individuals and household contacts of osteogenic sarcoma and hypernephroma patients, the number of individuals tested was sufficient to justify application of standard statistical tests, such as the Student $t$ test and the Welch test for comparison of two means. For the breast carcinoma series, it was felt that the Student $t$ test would be subject to severe criticism if applied to these data. We therefore used the Fisher-Irwin test for two by two tables, an exact test that does not depend on distribution assumptions.

\section{RESULTS}

The assay

Selection of cell lines. More than 25 cell lines were screened for suitability for this study. The first two criteria for selection were that they be tumor cells as measured by all available criteria (see Methods) and that their characteristics match those of their purported donor. The next criterion for selection was their suitability to the chromium-51 release assay. It was necessary that the total chromium-51 incorporation be high enough (usually over $3,000 \mathrm{cpm}$ ) and that the amount of chromium-51 released upon water lysis of the cell be sufficiently more than the spontaneous release level to give a measureable spread between the two values. In addition, the cell lines had to be stable enough in growth pattern to produce reliable values with all of

TABLE IV

Intrinsic Error of the Cytotoxicity Assay

Variation of Lymphocytes from the Same Individual, Drawn in Separate Syringes and Isolated and Assayed Individually

\begin{tabular}{|c|c|c|c|c|c|c|c|c|c|c|}
\hline \multirow[b]{2}{*}{ Cell line } & \multirow[b]{2}{*}{ Subject } & \multirow{2}{*}{$\begin{array}{l}\text { Lymphocyte: } \\
\text { target cell } \\
\text { tatio }\end{array}$} & \multicolumn{6}{|c|}{ Replicate samples } & \multirow[b]{2}{*}{ Averages } & \multirow[b]{2}{*}{$\mathrm{SD}$} \\
\hline & & & \multicolumn{2}{|c|}{ Aliquot 1} & \multicolumn{2}{|c|}{ Aliquot 2} & \multicolumn{2}{|c|}{ Aliquot 3} & & \\
\hline \multirow{9}{*}{ Te 85} & & & $C I$ & Average & $C I$ & Average & $C I$ & Average & & \\
\hline & 1 & $80: 1$ & 26.2 & 27 & 16.2 & 19.3 & 27.6 & 28.1 & 24.8 & 7.8 \\
\hline & & & 27.9 & & 22.5 & & 28.6 & & & \\
\hline & & $40: 1$ & 19.0 & 15.9 & 13 & 12.6 & 21.9 & 24.4 & 17.6 & $9.5 \ddagger$ \\
\hline & & & 12.8 & & 12.3 & & 26.9 & & & \\
\hline & 2 & $80: 1$ & 10.3 & 9.7 & 16.6 & 16 & ND & ND & 12.8 & 6.3 \\
\hline & & & 9.2 & & 15.4 & & & & & \\
\hline & & $40: 1$ & 4.7 & 5.1 & 11 & 9.1 & ND & ND & 7.1 & 2.0 \\
\hline & & & 5.5 & & 7.3 & & & & & \\
\hline \multirow[t]{2}{*}{ A 498} & 3 & $80: 1$ & 50.8 & 49.1 & 45.3 & 50 & 49.9 & 47.8 & 49.0 & 1.6 \\
\hline & & & 47.5 & & 54.8 & & 45.7 & & & \\
\hline
\end{tabular}

Daily Reproducibility: Comparison of CI Values between Lymphocytes Assayed Immediately after

Separation and Those from the same Lot Assayed on a Different Day, and Passage Level of Target Cells either Stored at $4^{\circ} \mathrm{C}$ for $24 \mathrm{~h}$, or Frozen in DMSO-

Containing Medium and Used from 1 wk to 1 mo Later

\begin{tabular}{|c|c|c|c|c|c|c|c|}
\hline Cell line & Subject & $\begin{array}{l}\text { Lymphocyte: } \\
\text { target cell } \\
\text { ratio }\end{array}$ & $\begin{array}{l}\text { CI, assayed } \\
\text { immediately }\end{array}$ & $\begin{array}{l}\mathrm{CI} \text { after } \\
\text { storage at } \\
4^{\circ} \mathrm{C}, 24 \mathrm{~h}\end{array}$ & $\begin{array}{l}\text { Storage } \\
\text { frozen }\end{array}$ & Average & $\mathrm{SD}^{*}$ \\
\hline \multirow[t]{4}{*}{ Te 85} & 4 & $80: 1$ & 35.8 & 43.4 & ND & 39.6 & 3.8 \\
\hline & 5 & $80: 1$ & 83.2 & ND & 92.4 & 87.8 & 4.6 \\
\hline & 6 & $80: 1$ & 34.1 & ND & 32.3 & 33.2 & 0.9 \\
\hline & 7 & $80: 1$ & 41.4 & ND & 34.8 & 38.1 & 3.3 \\
\hline
\end{tabular}

¥ The CI value at the 40:1 ratio, near the beginning of the plateau portion of the dose-response curve. demonstrates greater variation than the $C I$ value at the 80:1 ratio. 
TABLE V

Long-Term Reproducibility of CI Values

\begin{tabular}{|c|c|c|c|c|c|c|c|c|c|c|c|}
\hline \multirow[b]{2}{*}{ Cell line } & \multirow{2}{*}{$\begin{array}{l}\text { Lymphocyte } \\
\text { donor }\end{array}$} & \multirow[b]{2}{*}{ Diagnosis } & \multirow[b]{2}{*}{ Treatment } & \multicolumn{8}{|c|}{ Month } \\
\hline & & & & 1 & 2 & 3 & 4 & 4 & 5 & 6 & 7 \\
\hline & & & & & & & C & & & & \\
\hline \multirow[t]{3}{*}{ Te 85} & 1 & Normal & None & 76 & 70 & - & 66 & 68 & - & 74 & 72 \\
\hline & 2 & Normal & None & - & 41 & - & - & - & 48 & - & 40 \\
\hline & 3 & Osteosarcoma & Chemotherapy* & 50 & - & 65 & 63 & 51 & 65 & - & 一 \\
\hline A 498 & 3 & Osteosarcoma & Chemotherapy & 20 & - & - & 10 & 23 & 23 & - & 一 \\
\hline BT 20 & 4 & $\mathrm{HHC}_{\mathrm{br}}$ & None & - & - & - & 25 & 24 & 36 & 29 & - \\
\hline $\mathrm{ALAb}$ & 4 & $\mathrm{HHC}_{\mathrm{br}}$ & None & 110 & 126 & 94 & 96 & 96 & - & - & - \\
\hline $\mathrm{B}^{\prime} \mathrm{T} 20$ & 5 & Normal & None & - & - & 15 & - & - & 24 & - & - \\
\hline ALAb & 5 & Normal & None & - & - & 76 & - & - & 72 & - & - \\
\hline
\end{tabular}

* Adriamycin and 5-(3,3-dimethyl-1-triazeno) imidazole-4-carboxamide (DTIC).

the passage levels used from day to day. 10 of the 25 tumor cell lines screened were found suitable and the 4 tumor lines used most extensively in these studies had previously been especially well characterized (Table I).

Tumor-specific immunity was studied primarily against two of these cell lines, ALAb (breast carcinoma) and Te 85 (osteogenic sarcoma). Added precautions were taken to insure that these lines were not contaminated with mycoplasma. In addition to the routine screening procedure for mycoplasma, the entire lymphocyte-tumor cell preparations were randomly examined after incubation (on five separate occasions for each cell line) by scanning and transmission electron microscopy and were found in every case to be negative for mycoplasma.

A dose-response effect was noted with all target cell lines used in this assay (Fig. 1). The cytotoxicity index (CI) increased to a lymphocyte: target cell ratio of $40: 1$ and reached a plateau at higher ratios. The variation between replicate samples was minimal at the $80: 1$ ratio. Both the $40: 1$ and $80: 1$ ratios were tested at all times to ensure that the latter values were at the plateau portion of the curve and all CI values were reported at the $80: 1$ ratio.

Nature of the effector cell. To ascertain the nature of the cytotoxic effector cell, those cells that adhered to the tumor after the 3-h incubation period were examined as to their histology, their ability to form rosettes with SRBC, the presence of surface immunoglobulins, and their ability to be depleted by nylon wool columns. Examination of cover slip preparations showed that target cells with lymphocytes bound to their membranes could be found in various stages of destruction, but those with no bound lymphocytes looked relatively viable (Fig. 2). SRBC, added to the dishes after the incubation period, were found to bind to the adherent lymphocytes and thus formed T-cell-type rosettes. Observations by immunofluorescence on the target cells and adherent lymphocytes revealed that none of the lymphocytes that adhered to the target cells had membrane Ig, although roughly $20 \%$ of the cells added to the original incubation mixture contained such cells. The Ig-bearing cells seen adhered to areas of the cover slip and Petri dish that were free of tumor cells. Igbearing cells were also found in the supernatant (nonadherent) cells and in preparations of lymphocytes incubated in the absence of target cells.

Peripheral blood lymphocytes from three different individuals were depleted of their surface Ig-bearing cells by passage through nylon wool columns (eluate contains $1-2 \%$ Ig-bearing cells). The CI of these lymphocytes was compared to that of lymphocytes from the same individual, separated on Ficoll-Hypaque (15$21 \%$ Ig-bearing cells). The $\mathrm{CI}$ values were not significantly different (Table III).

Our results demonstrate that the cells that mediate tumor cell lysis in this assay are immunoglobulin-free, rosette-forming lymphocytes that do not adhere to nylon wool columns. We therefore consider that we are measuring T-cell-mediated cytotoxicity $(18,19)$.

Reproducibility. A series of experiments was designed to define the variation of this cytotoxicity assay and to locate the principal source of variability (Table IV).

Peripheral blood from one person was drawn into three separate syringes. The lymphocytes from each syringe were isolated separately on Ficoll-Hypaque, and then assayed. The resultant $\mathrm{CI}$ values, at ratios of $80: 1$ and $40: 1$, were compared. The broadest range ever obtained in a large series of experiments was 16 $\mathrm{CI}$ units, with an SD of $8 \mathrm{CI}$ units.

Lymphocytes from one person were separated on Ficoll-Hypaque and divided into three aliquots; the 
TABLE VI

Range of CI Values Produced by Lymphocytes from a Variety of Subjects against the Same Batch of Chromated Target Cells on the Same Day

\begin{tabular}{|c|c|c|c|c|c|}
\hline \multirow[b]{2}{*}{ Lymphocyte donor } & \multirow{2}{*}{$\begin{array}{l}\text { Lymphocyte } \\
\text { target cell } \\
\text { ratio }\end{array}$} & \multicolumn{2}{|c|}{ TE 85} & \multicolumn{2}{|c|}{ A 498} \\
\hline & & сpm* & $\mathrm{CI}$ & $\mathrm{cpm}^{*}$ & $\mathrm{CI}$ \\
\hline Patient with metastatic & $80: 1$ & 3,330 & 13.1 & 2,899 & 5.3 \\
\hline osteogenic sarcoma & $40: 1$ & 2,962 & 1.8 & 2,902 & 5.4 \\
\hline Patient with chemotheraputically & $80: 1$ & 5,338 & 74.9 & 4,237 & 23.3 \\
\hline controlled osteogenic sarcoma & $40: 1$ & 5,036 & 65.5 & 3,874 & 18.4 \\
\hline Patient with surgically & $80: 1$ & 7,941 & 154.9 & 3,890 & 18.7 \\
\hline $\begin{array}{l}\text { controlled giant cell } \\
\text { sarcoma of bone }\end{array}$ & $40: 1$ & 5,859 & 90.0 & 3,539 & 13.9 \\
\hline Normal household contact of & $80: 1$ & 4,482 & 48.5 & 4,168 & 22.4 \\
\hline patient with osteogenic sarcoma & $40: 1$ & 3,984 & 33.2 & 3,625 & 15.1 \\
\hline Normal individual with no & $80: 1$ & 3,141 & 7.3 & 3,514 & 8.1 \\
\hline $\begin{array}{l}\text { known contact with } \\
\text { cancer patients }\end{array}$ & $40: 1$ & 3,122 & 6.7 & 3,103 & 8.1 \\
\hline Media lysis & & 2,902 & & 2,800 & \\
\hline Water lysis & & 6,154 & & 9,929 & \\
\hline
\end{tabular}

* Mean of replicate samples.

first was assayed immediately, the second was placed at $4^{\circ} \mathrm{C}$ overnight and reassayed the next day, and the third was frozen in $10 \%$ DMSO-MEM-FCS, thawed several days or weeks later, and assayed. Thus CI values from the same pool of lymphocytes assayed on different days on different passage levels of target cells were compared. This procedure was repeated on four different subjects and the range of variation was no greater than $\pm 5 \mathrm{CI}$ units.

Daily reproducibility was assessed by selecting either normal healthy individuals with high or low levels of cytotoxicity or patients with one of the tumor types studied here whose condition was stable. Their CI values were tested over several-month intervals (Table V) and the variation in these subjects' CI's was less than the variation produced as a result of the FicollHypaque separations. We therefore conclude that the greatest source of variation is not in daily fluctuations of the assay itself or in the different passage levels of the target cells, but rather in the lymphocyte separation procedure. The maximal intrinsic variation of the technique is $\pm 8 \mathrm{CI}$ units.

Table VI illustrates the complete range of CI values that can be seen from the cytotoxity assay in 1 day. On this day, subjects included one normal individual with consistently low $\mathrm{CI}$, one patient with metastatic osteogenic sarcoma, one osteogenic sarcoma household contact with consistently high CI, and one patient with resected giant cell sarcoma of bone, a tumor that crossreacts with osteogenic sarcoma on a humoral level (20). It can be seen from the above results that on any given day individuals score high or low CI's depending on their immune specificities.

\section{Patients and household contacts}

Detection of tumor-specific immunity. The interaction between lymphocytes from normal individuals and all cell lines (tumor or normal) produces a certain level of chromium-51 release. This represents a background release level, the nature of which is unclear. This chromium release may be mediated by a variety of nonimmune mechanisms such as mechanical interactions, and subtle $\mathrm{pH}$ or ionic strength changes in the media, etc. Therefore "normal" ranges were established for each cell line. These ranges represent $\mathrm{CI}$ values falling within two $\mathrm{SD}$ of the mean of $\mathrm{CI}$ values produced by lymphocytes from normal persons with no known contact with the type of cancer (carcinoma vs. sarcoma) against which they were tested. Any value falling above the normal range was considered to be immune lysis. Populations were selected for tumor-specific immune lysis by removing all individuals who scored in the immune range on any control cell line. In this manner we select out individuals with non-tumor-specific (histocompatibility) immunity. These are often multiparous women.

Osteogenic sarcoma. Of the several available tumor cell lines that had been isolated from osteogenic sarcoma tumors, Te 85 was selected for use in this assay. It has been characterized as a tumor cell line, it was well suited for use in the chromium-51 release assay on the basis of range and reproducibility of lytic 
parameters, and the lymphocyte-mediated lysis correlated well with the clinical course of patients with osteogenic sarcoma. Individuals with tumor-specific immunity to $\mathrm{Te} 85$ also showed similar levels of immunity to a variety of other osteogenic sarcoma cell lines.

Normal range. 61 normal individuals with no known contact with sarcoma patients were tested on the cell line Te 85 (osteogenic sarcoma) and on one or more of the three control cell lines, A 498 (hypernephroma), BT-20, (breast carcinoma), and ALAb (breast carcinoma). The mean CI of these individuals was 23.3 with an SD of $10.8 \mathrm{CI}$ units. Any value above $44 \mathrm{CI}$ units on this cell line (2 SD above the mean) was considered significantly higher than normal and indicative of immunity against this cell line.

Household contacts, osteogenic sarcoma (HHCos). 111 normal household contacts of patients with osteogenic sarcoma were tested on the osteogenic sarcoma line, and one or more of the three control cell lines, A 498, BT-20, and ALAb. The range of CI values produced by these individuals on the osteogenic sarcoma line had a mean $\mathrm{CI}$ of $33.4 \mathrm{U}$, with a standard deviation of $22 \mathrm{CI} \mathrm{U}$ (Table VII). Statistical comparison of the CI values of this population of individuals with those of the normal individuals demonstrated a significant difference between them $(P<0.01)$ with the Student $t$ test. By the Welch approximation, an estimate of the difference of the means was 10.1, SD 2.53 , and $P<0.001$.

The control and the household contact populations were then adjusted to remove values provided by individuals who may have had non-tumor-specific immunity. This was done by removing the values from individuals who scored higher than $2 \mathrm{SD}$ from the mean of the normal range on any of the other control tumor cell lines (all individuals were tested on the A 498 line and often on one other cell line, BT-20 or

TABLE VII

Normal Individuals and Household Contacts of Cancer Patients Tested on Cell Lines Derived from Osteogenic Sarcoma, Hypernephroma, and Breast Carcinoma

\begin{tabular}{|c|c|c|c|c|}
\hline & \multicolumn{2}{|c|}{ Total population } & \multicolumn{2}{|c|}{ Corrected for specificity* } \\
\hline & Normal & HHC & Normal & HHC \\
\hline \multicolumn{5}{|c|}{ Tested on osteogenic sarcoma, TE 85} \\
\hline Number tested & 61 & 111 & 45 & 103 \\
\hline Mean CI & 23.3 & 33.4 & 21 & 32.1 \\
\hline SD & 10.8 & 22 & 11.2 & 22 \\
\hline CI $2 \mathrm{SD}$ above the mean & 44 & & & \\
\hline$P$ value & \multicolumn{2}{|c|}{$<0.018$} & \multicolumn{2}{|c|}{$<0.001$} \\
\hline \multicolumn{5}{|c|}{ Tested on hypernephroma, A 498} \\
\hline Number tested & 117 & 18 & 100 & 17 \\
\hline Mean CI & 22.5 & 21.3 & 21.6 & 19.5 \\
\hline SD & 15.6 & 15.5 & 17.0 & 12.7 \\
\hline CI 2 SD above the mean & 53 & & & \\
\hline$P$ value & \multicolumn{2}{|c|}{$0.5 \mathrm{NS}$} & \multicolumn{2}{|c|}{$0.5 \mathrm{NS}$} \\
\hline \multicolumn{5}{|c|}{ Tested on breast carcinoma, ALAb 496} \\
\hline Number tested & 14 & 13 & 14 & 13 \\
\hline Mean CI & 72.9 & 117.2 & 72.9 & 117.2 \\
\hline SD & 24.2 & 49.8 & 24.2 & 49.8 \\
\hline CI $2 \mathrm{SD}$ above the mean & 120.3 & & 120.3 & \\
\hline$P$ value & \multicolumn{2}{|c|}{$<0.01$} & \multicolumn{2}{|c|}{$<0.01$} \\
\hline \multicolumn{5}{|c|}{ Tested on breast carcinoma, BT 20} \\
\hline Number tested & 13 & 13 & 13 & 13 \\
\hline Mean CI & 25 & 14 & 25 & 14 \\
\hline SD & 28 & & & \\
\hline CI 2 SD above the mean & 81 & & 81 & \\
\hline$P$ value & \multicolumn{2}{|c|}{$0.5 \mathrm{NS}$} & & \\
\hline
\end{tabular}

* All values from individuals scoring more than $2 \mathrm{SD}$ above the mean on the control cell lines were removed.

$\ddagger$ These data were also analyzed by the Fisher-Irwin test; see text.

$\S$ These data were also analyzed by the Welch test; see text. 


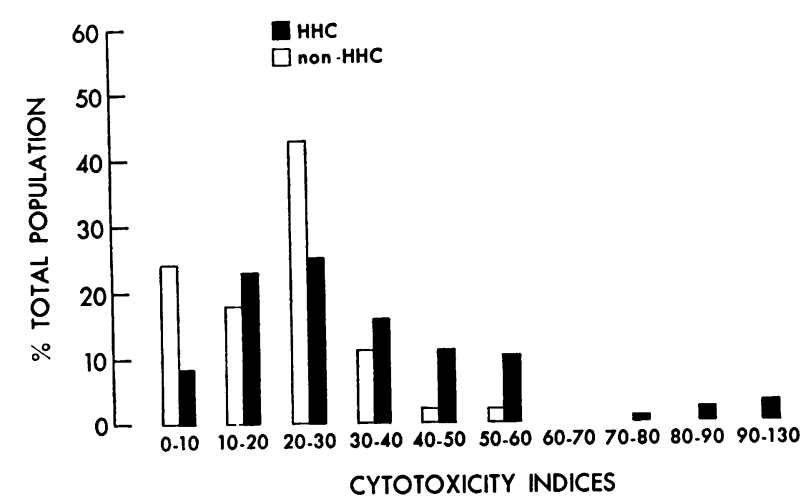

FIGURE 3 The reactions of lymphocytes from 45 normal individuals with no known contact with patients with sarcomas compared with 99 household contacts of patients with osteogenic sarcoma. Lymphocytes were assayed for CI on an osteogenic sarcoma-derived cell line ( $\mathrm{Te} 85$ ) and a hypernephroma-derived cell line (A 498). The lymphocytes from individuals included on this bar graph were corrected for specificity; only those scoring in the normal range on the hypernephroma-derived cell line (2 SD above the mean of the normal population) are included. The difference between the two populations, household contacts and normals, is statistically significant to a $P$ value of 0.001 .

$A L A b)$. These corrected populations were found to be significantly different by the Student $t$ test $(\mathrm{P}<0.001)$ (Fig. 3).

$26 \%(29 / 111)$ of the HHCos scored above $44 \mathrm{CI}$ units on $\mathrm{Te} 85$ (osteogenic sarcoma), while scoring within the normal range on control cell lines. 3\% $(2 / 61)$ of the normal individuals had this type of immunity. One of these two was a pathologist.

Although most of the HHCos who demonstrated tumor-specific immunity on the $\mathrm{Te} 85$ cell line were genetically related to the patients (24/94), tumorspecific immunity was also found in 5 of 17 genetically unrelated household contacts, including household servants, guardians, and spouses. The incidence of immunity in both populations is the same, $25 \%$ and $29 \%$, respectively. Although the number of genetically unrelated household contacts is small, comparison with the control (normal) group by use of the Fisher Irwin test demonstrated that the difference between the two groups is statistically significant (to the $P=0.014$ level).

Patients-osteogenic sarcoma. Only 3 of 12 patients with osteogenic sarcoma demonstrated positive cellmediated immunity against osteogenic sarcoma before immunotherapy. This immunity was seen just before or just after amputation, when the primary tumor was quite small, and disappeared some time after amputation. The reaction of one such patient is shown in Fig. 1. Similar specificity was seen in the other two patients tested. These reactions are discussed in another paper (21).

Two patients with metastases had very low CI against osteogenic sarcoma before resection of the metastatic lesions. These CI's increased sharply after surgery. Four patients with giant cell sarcoma of bone also demonstrated positive specific immunity against the osteogenic sarcoma tumor line.

Hypernephroma-normal range. 117 normal individuals with no known contact with carcinoma patients were tested on the hypernephroma line A 498 and the other control cell lines (primarily $\mathrm{Te} 85$, osteogenic sarcoma). The mean CI value on the hypernephroma cell line (A 498) for the normal population was 22.5 (SD 15.6). Therefore, any CI on this cell line above $53 \%$ (2 SD above the mean) was considered above the normal range and indicative of tumor-specific cellular immunity against this cell line.

Hypernephroma household contacts $\left(H C C_{\mathrm{An}}\right) .18$ $\mathrm{HHC}_{\mathrm{hn}}$ were tested on these lines. The CI values from these individuals were not significantly different from the normals. Correcting these populations by eliminating individuals with "nonspecific" immunity did not produce any significant change. (Fig. 4).

Hypernephroma patients. Nine patients with hypernephroma were tested and none were found to have $\mathrm{CI}$ values above the normal range.

The A 498 cell line appears to be excellent for detecting non-tumor-specific T-cell immunity. Individuals with high CI's on this line were also found to have high CI's on most of the other tumor lines tested. An

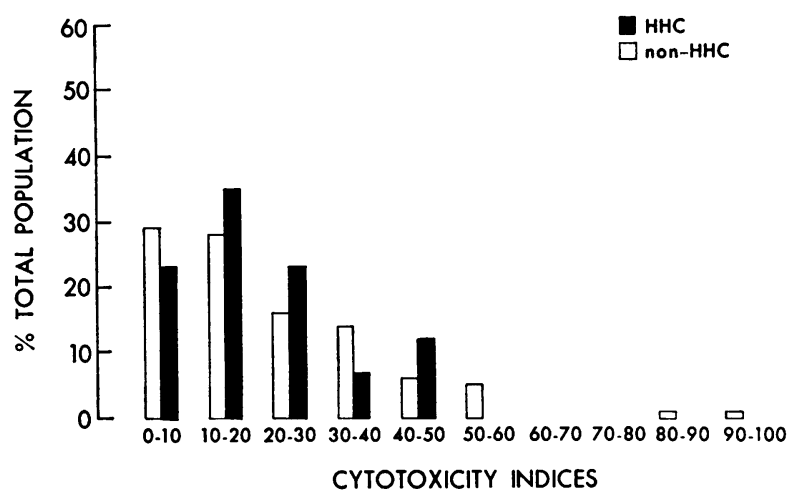

FIGURE 4 Comparison of the cytotoxicity indices of 17 household contacts of patients with hypernephroma with those of 100 normal individuals with no known history of contact with carcinoma patients. The lymphocytes were assayed against a hypernephroma-derived cell line (A 498) and a cell line derived from an osteogenic sarcoma. Only the reactions of those individuals scoring within the normal range on the osteogenic sarcoma-derived cell line are included in this bar graph. The two populations, household contacts and normals, are not statistically significantly different. 
example of one such individual was a 50-yr-old woman who scored $160 \mathrm{CI}$ on A 498, $39 \mathrm{CI}$ on BT-20, $183 \mathrm{CI}$ on ALAb 496, and 52 on Te 85. All of her maternal and paternal relatives had died of carcinomas, and her husband had active carcinoma.

That this line (A 498) is capable of being lysed by lymphocytes, but does not detect tumor-specific immunity in patients with hypernephroma nor in $\mathrm{HHC}_{\mathrm{nn}}$ raised the question as to whether it had lost its T-celldefined tumor-specific antigens. Therefore, four of the hypernephroma patients and five of their $\mathrm{HHC}$ were tested on two additional hypernephroma lines, Hs 715T, and $\mathrm{Hs}$ 699T, and their matching fibroblast lines (derived from skin or kidney). In no case did the lymphocytes produce higher CI values on the tumor cell lines than on the genetically matched benign cell lines.

Breast carcinoma-normal range. Six cell lines derived from breast carcinomas were tested for possible use in this assay. Two lines, BT-20 and ALAb 496, were found suitable for use in this assay. Both are secretory epithelial cell lines (10). The other four were unsatisfactory for the following reasons: HBT 3 (22) and HBT 39B (23) were found to be HeLa cells (8). 734B (24) had growth characteristics that produced unreproducible day-to-day results. MDA-MB 157 (25) had a spontaneous release chromium-51 value too high for use (too close to the water lysis value).

Normal individuals, both men and women, with no known contact with patients with carcinoma were tested on BT20 and ALAb 496 and on the control tumor cell lines, A 498 and Te 85 . The mean CI of this population was 25 on BT-20, and 73 on ALAb 496. Therefore the immune range was above $81 \mathrm{CI}$ on BT-20 and $120 \mathrm{CI}$ on ALAb. All of these individuals had CI values in the normal range on the control cell lines.

Breast carcinoma-household contacts ( $\left.H H C_{b r}\right)$. 13 household contacts of breast carcinoma patients who had had mastectomies within the past $5 \mathrm{yr}$ were assayed against the two breast carcinoma lines (Fig. 5) and the control tumor cell lines. All were in the normal range on the control tumor cell lines. The two populations, normals and household contacts, were not significantly different in the range of $\mathrm{CI}$ values produced on the BT-20 line but were markedly different on the ALAb line.

7 of 13 household contacts tested (54\%) produced CI values greater than $2 \mathrm{SD}$ above the mean of the normal range on the ALAb line. The two populations were analyzed by the Student $t$ test and found to be statistically significantly different $(P=0.001$, Table VII). However the validity of this test as used on these values is questionable, since the populations being compared do not form normal bell-shaped curves. The CI values of the $\mathrm{HHC}_{\mathrm{br}}$ clearly fell into two distinct
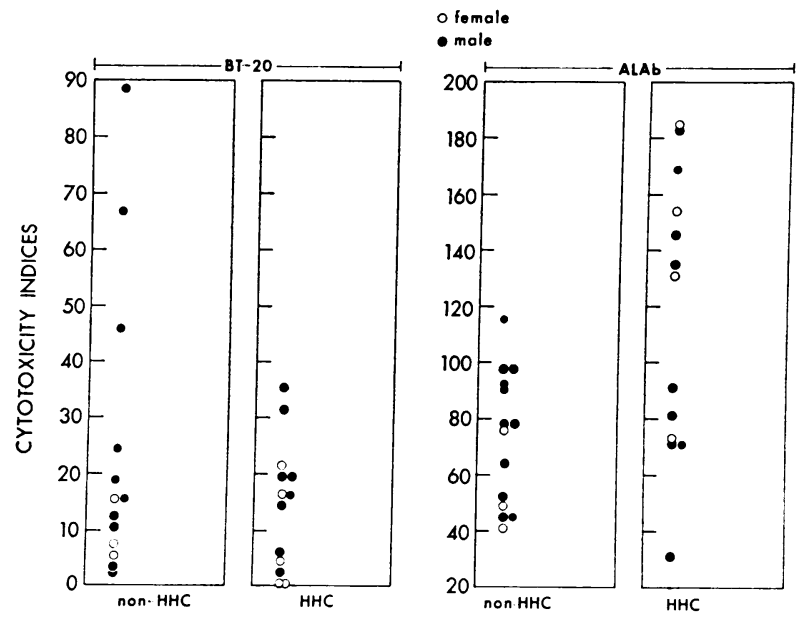

FIgURE 5 Comparison of cytotoxicity indices of 13 household contacts of patients who had active breast carcinoma either at the time of testing or within the past three years, to those of 14 normal individuals with no known exposure to patients with carcinoma. Lymphocytes were assayed on two cell lines derived from breast carcinoma, BT-20, and $\mathrm{ALAb}$, and on A 498 (hypernephroma), and Te 85 (osteogenic sarcoma). Lymphocytes from all individuals whose reactions are shown in these scatter graphs showed CI in the normal range (2 SD above the mean of the normal range) on the latter two lines. Comparison of these two populations, household contacts and normals, demonstrated no statistically significant differences when assayed against BT-20. However, the reactions on ALAb were significantly different to a $P$ value of 0.01 as compared by the Student $t$ test, or to a level of $P=0.002$ compared by the FisherIrwin test.

ranges, neither bell-shaped. They were therefore compared by the Fisher-Irwin test, in which the number proportion of normal individuals whose CI levels were greater than 120 ( $2 \mathrm{SD}$ above the mean of the normal population) were compared with those with CI below 120 , without regard to exact values. When compared in this fashion, the two populations, normal and $\mathrm{HHC}_{\mathrm{br}}$, were again found to be significantly different $(P<$ $0.002)$.

The immunity to breast carcinoma, as measured on the ALAb line, was equally divided between men and women and, again, there was an equal percentage of genetically related household contacts and genetically unrelated household contacts (husbands, adopted children) demonstrating tumor-specific immunity $(3 / 7$ and 4/7). These populations were too small to be statistically analysed. Since the data were analyzed and the graphs made, 14 more individuals have been tested in this system and their CI results are concordant with the ranges described here.

Breast carcinoma-patients. Four patients with breast carcinoma were tested on four cell lines: ALAb, $\mathrm{BT}-20$, and the two specificity control lines, Te 85 and 
A 498. All four patients had had mastectomies 2-5 yr previously. The two patients clinically disease-free at the time of testing had CI's above the normal range on the ALAb line and within the normal range on the other cell lines. The other two patients, both with large liver metastases at the time of testing, were within the normal "nonimmune" range.

\section{DISCUSSION}

Experiments were performed to determine if individuals who are exposed to patients with cancer develop tumorspecific, cell-mediated immunity. The assay used, a short term chromium-51 release assay, is highly reproducible and measures cytolysis of tumor cells mediated by peripheral blood lymphocytes, which by presently accepted parameters are $\mathrm{T}$ lymphocytes.

Lymphocytes from normal individuals (with no known contact with the tumors against which they were tested) were assayed for cytolytic activity against osteogenic sarcoma, hypernephroma, and breast carcinoma cells in tissue culture. Normal ranges of CI values were established for each cell line. The nonimmune range was considered to include $\mathrm{CI}$ values 2 SD from the mean.

Healthy household contacts of patients with osteogenic sarcoma, hypernephroma, or breast carcinoma were also tested against the cell lines. Household contacts of osteogenic sarcoma patients were found to produce a range of $\mathrm{CI}$ values against osteogenic sarcoma, the mean of which was significantly higher than that of the normal population $(P<0.001)$. This difference was more pronounced when the populations were corrected for tumor specificity.

Household contacts of, and patients with, breast carcinoma were tested against two cell lines derived from breast carcinoma and against two other lines (A 498, hypernephroma, and Te 85 , osteogenic sarcoma) used as specificity controls. One line, ALAb, proved to be an excellent indicator for tumor-specific immunity. Almost $50 \%$ of these patients with breast carcinoma and their household contacts demonstrated $\mathrm{CI}$ values above the normal range. Simultaneous tests on the other line, BT-20 (equally well documented as a breast carcinoma line), demonstrated no $\mathrm{CI}$ values in the immune range from either group.

The values of a normal population and of the household contacts of breast carcinoma patients were found to be significantly different when analyzed with the Student $t$ test; however, the non-normal distribution of the values of household contacts of these patients raised a question as to the value of this test. Therefore the Fisher-Irwin test for two by two tables was used to analyze these data. Again the values proved significantly different $(P<0.002)$.
Tumor-specific immunity both to breast carcinoma and osteogenic sarcoma was evenly divided between men and women. This is especially interesting in the case of breast carcinoma, in which the incidence in women is 87 per 100,000 population (in the San Francisco Bay area) and in men is 0.8 per 100,000 population, same area. ${ }^{2}$ However, the incidence of tumorspecific immunity among the household contacts of breast carcinoma patients was much higher than those of osteogenic sarcoma patients (almost $50 \%$ as opposed to $26 \%$ ), and the $\mathrm{CI}$ values fell in a much higher range. This difference may be methodological and may reflect the indicator cell line or it may be related to the higher incidence of breast cancer than of osteogenic sarcoma $(0.4 / 100,000$ population, San Francisco Bay area).

Tumor-specific immunity tended to cluster in households; a disproportionately high number of individuals with immunity was found in some households and none in others. The immunity was noted both in genetically related household contacts of individuals with the tumor and in unrelated household contacts (husbands, guardians, adopted children). With both tumor types, the percent of immune household contacts was almost exactly the same, whether genetically related or not.

The higher incidence of immunity clustering among individual families is probably not based on immunity against histocompatibility antigens on the test target cell, since the immunity is found in unrelated household contacts with a frequency equal to that of related household contacts. Also, no more than one member of a family ever reacted against tumors to which they were not exposed, and that was usually a multiparous mother.

This immunity is not directed against nonspecific factors such as mycoplasma, fetal calf serum antigens, or other non-tumor-associated antigens, since that type of immunity would be randomly distributed in all populations. This immunity is not found randomly in normals exposed to cancer of any type since many of the "non-household contact" controls for the carcinoma lines were household contacts of osteogenic sarcoma patients and vice versa. On no occasion was a household contact of one tumor type found to have tumorspecific immunity to a different tumor type.

The primary evidence that this assay, as described, actually measured tumor-specific cell-mediated immunity to either osteogenic sarcoma or breast carcinoma rests on the clinical correlates of the assay. Breast carcinoma provides the more obvious case; of the four patients tested with breast carcinoma who had had mastectomies within the past $3 \mathrm{yr}$, two demonstrated

\footnotetext{
${ }^{2}$ California State Department of Public Health, California Tumor Registry, Berkeley, Calif.
} 
specific immunity to breast carcinoma. The remaining two patients had CI values in the low normal range and both of these individuals had extensive metastatic disease.

Osteogenic sarcoma patients demonstrated a complex pattern of immunity more fully described in another paper (21). Tumor-specific immunity was found in patients with small tumors immediately before and after amputation of the tumors and it was gradually lost after the antigenic mass was removed. Two patients demonstrated sharp increases in tumor-specific immunity after their metastatic tumors were resected, possibly because the antigen mass was serving as a "sink" for immune lymphocytes.

The hypernephroma cell line proved to be a sensitive indicator line for $\mathrm{T}$-cell immunity against cellular antigens (Fig. 4), but there was no evidence of tumor immunity found with this line in patients with hypernephroma or in their household contacts. Either there is, in fact, no detectable T-cell-defined tumorspecific immunity in these individuals or, if present, it has a low incidence (since 18 household contacts and 4 patients were found negative), or such antigens on the hypernephroma tumors from different patients do not cross-react. Alternatively, the hypernephroma line A 498 may have lost the antigens responsible for tumorspecific T-cell-mediated lysis. Levy (26) reported recently that cultured tumor cells occasionally lose their cellular antigens with increasing passage levels. We have reported a case in which the antigenic density steadily decreased from the primary tumor through the different passage levels of the tumor cell line. ${ }^{3}$ Other such cases have also been reported (27). However, patients and their household contacts were also tested on two other hypernephroma lines with the matching fibroblast cell lines and there was no difference between the cytolysis on the tumor cell lines and the benign cell lines. Baldwin, Embleton, Jones, and Langman reported the results of studies of tumor-specific cell-mediated immunity on patients with carcinomas of colon, rectum, breast, kidney, and lung, and a melanoma. They found that autochthonous lymphocytes from patients with the above tumors were cytotoxic, with the exception of bronchogenic carcinoma and hypernephromas. These investigators also found that $50 \%$ of breast carcinoma patients have tumor-specific cell-mediated immunity against this tumor (28).

A second case of negative reactivity was the breast carcinoma cell lines, one of which, ALAb, proved an excellent indicator for tumor-specific immunity, but

${ }^{3}$ Byers, V. S., A. S. Levin, J. O. Johnston, A. J. Hackett, H. H. Fudenberg. 1975. Quantitative immunofluorescent studies of the tumor-antigen-bearing cell in giant cell sarcoma of bone. Cancer Res. (revised ms submitted Jan. 1975). the other, BT-20, did not produce CI values above the normal range with either patients or their household contacts. Sinkovićs has used the BT-20 line in studies on breast carcinoma patients. He used a modification of the colony inhibition assay, which involves a 3-4 day incubation of the lymphocytes and target cells. We used a 3-h incubation with the chromium-51 release assay. He reports that this cell line was a sensitive indicator for tumor-specific immunity (29). Colony inhibition has been reported to be more sensitive than the chromium-51 release assay (detecting immunity under circumstances in which the latter is negative); but there is some question as to its specificity (30).

The reason for the discrepancies found between the two assays may be that there are two types of antigenspecific $T$ lymphocytes. In mice these are called $\mathrm{T}-1$ and $\mathrm{T}-2$. The short-term chromium-51 release assay detects the activity of the most mature population, $\mathrm{T}-2$ (31). The longer incubation time may allow the immature $\mathrm{T}-1$ population to differentiate into mature $\mathrm{T}-2$ cells. The colony inhibition assay may, therefore, be measuring both $\mathrm{T}-1$ and $\mathrm{T}-2$ lymphocytes.

It is interesting that transfer factor made from leukocytes that demonstrate activity by the chromium51 release assay is capable of transferring cell-mediated immunity from donor to patient (21). This suggests that this factor may be found in the T-2 population.

The results of this study correlate with findings of other investigators. Morton and Malmgren reported that $80-90 \%$ of relatives of osteogenic sarcoma patients had antisarcoma antibodies as measured by immunofluorescence, and that $29 \%$ of the normal population also had this immunity (2). In a later report, Eilber and Morton also demonstrated antisarcoma immunity in $60-100 \%$ of relatives of patients with synovial cell sarcoma, rhabdomyosarcoma, or fibrosarcoma (4). Priori, Wilbur, and Dmochowski (32) confirmed the increased incidence of antibody to osteogenic sarcoma in relatives of these patients. Their figures, however, demonstrated an incidence of immunity in $30 \%$ of relatives and $5 \%$ in normal individuals. They also used immunofluorescence. Hellström and Hellström reported cellular immunity directed against neuroblastoma in mothers of children with this tumor (6). Since all of these studies were performed on relatives of cancer patients, they have provided indirect evidence for a transmissible agent, either horizontal or vertical, in these tumors.

This report confirms the increased incidence of immunity among contacts of patients with breast carcinoma and osteogenic sarcoma. Although this incidence is much lower than that reported by Morton and Malgren, it is almost exactly that reported by Priori et al. This may reflect either greater specificity or decreased 
sensitivity in the various assays used. It does seem clear, however, that genetic relationship to a cancer patient is not necessary for immunity. This suggests that the immunogen is transmitted horizontally. We cannot speculate on vertical transmission from these data.

\section{ACKNOWLEDGMENTS}

We wish to thank Professor L. LeCam, Department of Statistics, University of California at Berkeley, for his advice and critical review of the statistical analysis of these data. We wish also to thank Drs. M. McCoombs and G. Fisher for their assistance with the statistical analysis of the data. We wish to thank Dr. M. Shiffrin for critical review of the data, Dr. W. Nelson-Rees for analysis of the characteristics of the cell lines listed here, and Ms. Emma Stump for editorial assistance. We especially are grateful for the technical assistance of Mr. Eddie Bautista and Miss Ann Merrill Knapp.

This work was supported in part by U.S. Public Health Service Grant HD 05894, by National Cancer Institute Virus Cancer Program Contract E 73-2001-N01-CP-3-3237, and by U. S. Public Health Service NIH Training Grant HL-05677.

\section{REFERENCES}

1. Hellström, I., K. E. Hellström, A. H. Bill, G. E. Pierce, and J. P. S. Yang. 1970. Studies on cellular immunity to human neuroblastoma cells. Int. J. Cancer. 6: 172188.

2. Morton, D. L., and R. A. Malmgren. 1968. Human osteosarcomas: immunologic evidence suggesting an associated infectious agent. Science (Wash. D. C.). 162: 1279-1281.

3. Morton, D. L., W. T. Hall, and R. A. Malmgren. 1969. Human liposarcomas: tissue cultures containing foci of transformed cells with viral particles. Science (Wash. D. C.). $165: 813-816$.

4. Eilber, F. R., and D. L. Morton. 1970. Immunologic studies of human sarcomas: additional evidence suggesting an associated sarcoma virus. Cancer. 26: 588596.

5. Morton, D. L., R. A. Malmgren, W. T. Hall, and G. Schidlovsky. 1969. Immunologic and virus studies with human sarcomas. Surgery (St. Louis). 66: 152-161.

6. Hellström, K. E., and I. Hellström. 1974. Lymphocytemediated cytotoxicity and blocking serum activity to tumor antigens. Adv. Immunol. 18: 209-277.

7. Lasfargues, E. Y., and L. Ozzello. 1958. Cultivation of human breast carcinomas. J. Natl. Cancer Inst. 21: $1131-1147$.

8. Nelson-Rees, W. A., R. R. Flandermeyer, and P. K. Hawthorne. 1974. Banded marker chromosomes as indicators of intraspecies cellular contamination. Science (Wash. D. C.). 184: 1093-1096.

9. Arnstein, P., D. O. N. Taylor, W. A. Nelson-Rees, R. J. Huebner, and E. H. Lennette. 1974. Propagation of human tumors in antithymocyte serum-treated mice. J. Natl. Cancer Inst. 52: 71-84.

10. Buehring, G. C., and A. J. Hackett. 1974. Human breast tumor cell lines: identity evaluation by ultrastructure. J. Natl. Cancer Inst. 53: 621-629.

11. Reed, M. V., and G. O. Gey. 1962. Cultivation of normal and malignant human lung tissue. I. The establishment of three adenocarcinoma cell strains. Lab. Invest. 11: 638-652.

12. Giard, D. J., S. A. Aaronson, G. J. Todaro, P. Arnstein, J. A. Kersey, H. Dosik, and W. P. Parks. 1973. In vitro cultivation of human tumors: establishment of cell lines derived from a series of solid tumors. J. Natl. Cancer Inst. 51 : 1417-1423.

13. MacAllister, R. M., M. B. Gardner, A. E. Greene, C. Bradt, W. W. Nichols, and B. H. Landing. 1971. Cultivation in vitro of cells derived from a human osteosarcoma. Cancer. 27 : 397-402.

14. Owens, R. B. 1974. Glandular epithelial cells from mice, a method for selective cultivation. J. Natl. Cancer Inst. 52: 1375-1378.

15. Julius, M. H., E. Simpson, and L. A. Herzenberg. 1973. A rapid method for the isolation of functional thymusderived murine lymphocytes. Eur. J. Immunol. 3: 645649.

16. Henney, C. S. 1973. Studies on the mechanism of lymphocyte-mediated cytolysis. II. The use of various target cell markers to study cytolytic events. J. Immunol. 110: 73-84.

17. Bunting, W. L., J. M. Kiely, and C. A. Owens, Jr. 1963. Radiochromium-labeled lymphocytes in the rat. Proc. Soc. Exp. Biol. Med. 113: 370-374.

18. Papamichail, M., J. C. Brown, and E. J. Holborow. 1971. Immunoglobulins on the surface of human lymphocytes. Lancet. 2: 850-852.

19. Wybran, J., and H. H. Fudenberg. 1973. Thymus-derived rosette-forming cells in various human disease states: cancer, lymphoma, bacterial and viral infections, and other diseases. J. Clin. Invest. 52: 1026-1032.

20. Mukherji, B., and Y. Hirshaut. 1973. Evidence for fetal antigen in human sarcoma. Science (Wash. D. C.). $181: 440-442$.

21. Levin, A. S., V. S. Byers, H. H. Fudenberg, J. Wybran, A. J. Hackett, and J. O. Johnston. 1975. Osteogenic sarcoma. Immunologic parameters before and during immunotherapy with tumor-specific transfer factor. $J$. Clin. Invest. 55 : 487-499.

22. Bassin, R. H., E. J. Plata, B. I. Gerwin, C. F. Mattern, D. K. Haapala, and E. W. Chu. 1972. Isolation of a continuous epithelioid cell line, HBT-3 from a human breast carcinoma. Proc. Soc. Exp. Biol. Med. 141: 673-680.

23. Plata, E. J., T. Aoki, D. D. Robertson, E. W. Chu, and B. I. Gerwin. 1973. An established cultured cell line (HBT-39) from human breast carcinoma. J. Natl. Cancer Inst. 50: 849-862.

24. Soule, H. D., J. Vasquez, A. Long, S. Albert, and M. Brennan. 1973. A human cell line from a pleural effusion derived from a breast carcinoma. J. Natl. Cancer Inst. $51: 1409-1416$.

25. Young, R. K., R. Cailleau, D. Mackay, and W. J. Reeves, Jr. 1974. Establishment of epithelial cell line MDA-MB-157 from metastatic pleural effusion of human breast carcinoma. In Vitro. 9: 239-245.

26. Levy, N. L. 1973. Use of an in vitro microcytotoxicity test to assess human tumor specific cell mediated immunity and its serum-mediated abrogation. Natl. Cancer Inst. Monogr. 37: 85-92.

27. Moore, M., P. J. Witherow, C. H. G. Price, and S. A. Clough. 1973. Detection by immunofluorescence of intracytoplasmic antigens in cell lines derived from human sarcomas. Int. J. Cancer. 12: 428-437.

28. Baldwin, R. W., M. J. Embleton, J. S. P. Jones, and M. J. S. Langman. 1973. Cell-mediated and humoral 
immune reactions to human tumors. Int. J. Cancer. 12: 73-83.

29. Sinkovićs, J. G. 1973. Monitoring in vitro of cell-mediated immune reactions to tumors. Methods Cancer Res. 8: $107-175$.

30. Takasugi, M., M. R. Mickey, and P. I. Terasaki. 1973. Reactivity of lymphocytes from normal persons on cultured tumor cells. Cancer Res. 33: 2898-2902.
31. Stobo, J. D., W. E. Paul, and C. S. Henney. 1973. Functional heterogeneity of murine lymphoid cells. IV. Allogeneic mixed lymphocyte reactivity and cytolytic activity as functions of distinct $\mathrm{T}$ cell subsets. J. Immunol. 110: 652-660.

32. Priori, E. S., J. R. Wilbur, and L. Dmochowski. 1971. Immunofluorescence tests on sera of patients with osteogenic sarcoma. J. Natl. Cancer Inst. 46: 1299-1308. 